\title{
Artigos
}

\section{Estigmatização: consequências e possibilidades de enfrentamento em Centros de Convivência e Cooperativas}

Stigmatization: consequences and the potential for tackling the problem in Centers for Coexistence and Cooperatives (abstract: p. 16)

Estigmatización: consecuencias y posibilidades de enfrentamiento en Centros de Convivencia y Cooperativas (resumen: p. 16)

\author{
Adriana Leão(a) \\ <drileao@gmail.com> \\ Isabela Aparecida de Oliveira Lussi ${ }^{(b)}$ \\ <bellussi@ufscar.br>
}

\author{
(a) Departamento de Terapia \\ Ocupacional, Centro \\ de Ciências da Saúde, \\ Universidade Federal do \\ Espírito Santo. Avenida \\ Marechal Campos, 1.468, \\ Maruipe. Vitória, ES, Brasil. \\ 29047-105. \\ (b) Programa de Pós-Graduação \\ em Terapia Ocupacional, \\ Departamento de Terapia \\ Ocupacional, Universidade \\ Federal de São Carlos. São \\ Carlos, SP, Brasil.
}

Os efeitos negativos do estigma são um problema significativo em todo o mundo e, para tanto, buscase aumentar a conscientização e a compreensão das estratégias mais eficazes para combater os estigmas. No âmbito das políticas públicas de saúde, a convivência que promove e intensifica o contato entre as pessoas, com ou sem vulnerabilidades específicas, é intencionalmente promovida pelos Centros de Convivência e Cooperativas (Ceccos). Objetivamos nesse artigo compreender as concepções acerca do processo de estigmatização por meio da visão de profissionais. A análise do discurso resultou em unidades de significação, entre as quais as compreensões em torno de tipos, consequências e possibilidades para o enfrentamento dos estigmas. Não obstante os problemas estruturais e macrossociais presentes, há persistência no trabalho cotidiano diante das possibilidades de transformações observadas no contexto do serviço.

Palavras-chave: Estigma social. Saúde pública. Saúde mental. Serviços de saúde.

Leão A, Lussi IAO. Estigmatização: consequências e possibilidades de enfrentamento em Centros de Convivência e Cooperativas. Interface (Botucatu). 2021; 25: e200474 


\section{Introdução}

O estigma é um problema significativo em todo o mundo e, devido aos seus efeitos devastadores, estudos recentes na literatura internacional têm como objetivo aumentar a conscientização e a compreensão das estratégias mais eficazes para combater o estigma e a discriminação. A redução do estigma e da discriminação associada ao sofrimento psíquico tem se tornado um foco cada vez mais importante para a política e os programas de intervenção ${ }^{1}$.

Goffman ${ }^{2}$ define estigma como uma discrepância entre a identidade social real de alguém, aquilo que ele é, e a identidade social virtual, o caráter imputado ao indivíduo pelos outros, ou seja, uma caracterização com base nas expectativas de como ele deve ser. Torna-se assim uma linguagem de relações e não especificamente se refere a um atributo físico, psíquico, moral, de raça, nação ou religião.

Desse modo, o estigma social ou público é uma crença errônea acerca da identidade de uma pessoa, em que ela é considerada como menor, menos igual e pertencente a um grupo inferior, o que produz uma incorporação no âmbito social e cria a inferioridade. Essa identidade virtual se relaciona aos períodos cultural, econômico, político e histórico, sendo então um processo social contextualizado e não individual. A estigmatização produz desigualdade social, perda de direitos e cidadania e seus efeitos negativos referem-se aos prejuízos do trabalho e, consequentemente, ao ganho financeiro, à habitação, à saúde e aos laços sociais ${ }^{3}$.

Corrigan ${ }^{4}$ define estratégias antiestigma permeadas em três processos: protesto, educação e contato. O protesto pontuado como uma ferramenta benéfica para que as pessoas repensem seus comportamentos; a educação como abordagem para desmistificar o sofrimento psíquico atrelado a periculosidade, incompetência e outros estereótipos negativos, por meio de livros, folhetos, palestras, filmes, vídeos e serviço mediado no território; e o contato como essencial para diminuir o preconceito e com isso possibilitar que o sujeito se sinta incluído na sociedade de maneira integral. O contato, particularmente, apresenta-se como a estratégia antiestigma com mais resultados positivos.

No contexto brasileiro e no âmbito das políticas públicas de saúde, a convivência que promove e intensifica o contato é intencionalmente promovida pelos centros de convivência, que têm como premissa a oferta de espaços de sociabilidade, produção e intervenção cultural na cidade. Esses serviços que compõem a Rede de Atenção Psicossocial (Raps) $)^{5}$ objetivam a promoção da convivência e da inclusão social por meio da oferta de diferentes açóes de cultura, meio ambiente, esporte, educação, e pela inserção no mundo do trabalho, e buscam integrar as diferentes populaçóes, com e sem vulnerabilidades específicas, que frequentam os espaços públicos da cidade. São denominados também como Centros de Convivência e Cultura (Cecos) e ainda, Centros de Convivência e Cooperativa (Ceccos).

Especificamente, os Ceccos existem na cidade de São Paulo há mais de vinte anos, são pioneiros e originários do processo da Reforma Psiquiátrica e foram regulamentados pela Portaria 964/2018, que estabelece diretrizes para seu melhor funcionamento e afirma a importância desse equipamento para a consolidação das políticas públicas de Saúde e de Saúde $\mathrm{Mental}^{6}$. 
Diante da importância do contato para o enfrentamento da estigmatização e da existência de serviços específicos para a promoção da convivência entre as pessoas com as suas singularidades, justificamos a investigação realizada pela presença ainda incipiente da temática na produção científica brasileira, em comparação com a literatura internacional ${ }^{7}$, e partimos da questão: quais compreensões acerca da estigmatização permeiam o saber-fazer de alguns dos profissionais que lidam cotidianamente com o enfrentamento da estigmatização?

A participação social é uma das principais áreas de ocupação afetada pelos efeitos negativos da presença dos estigmas. O terapeuta ocupacional é um dos profissionais integrantes da equipe interdisciplinar que tem como foco a participação plena das pessoas nas açốes e nas relaçôes sociais. Assim, acredita-se que, como os demais profissionais, o terapeuta ocupacional apresenta importante contribuição para a diminuição da estigmatização. Além disso, investigar as concepçóes desse profissional sobre o processo de estigmatização possibilita ampliar e sistematizar a participação dessa categoria profissional no enfrentamento dos estigmas. Dessa forma, não foram contemplados outros profissionais nesta pesquisa que foi de curta duração.

Buscamos conhecer a construção discursiva dos terapeutas ocupacionais acerca do processo de estigmatização de uma parte da população usuária dos Ceccos que apresenta diferentes formas de ser e estar no mundo.

Desse modo, o objetivo deste artigo é compreender as concepçóes presentes no processo de estigmatização (barreiras, tipos, consequências e possibilidades), como resultado de uma das unidades de significação dos discursos dos terapeutas ocupacionais dos Ceccos da cidade de São Paulo.

\section{Percurso metodológico}

Trata-se de pesquisa de abordagem qualitativa e tem como referencial teórico norteador os estudos de Goffman ${ }^{2}$ e a produção de autores que tratam da temática da estigmatização no campo da Saúde, especificamente da Saúde Mental.

O campo deste estudo foram os Ceccos de São Paulo por ser a convivência intensificadora do contato como uma estratégia importante de enfrentamento ${ }^{4}$. Por meio da oferta de diferentes ações de cultura, meio ambiente, esporte, educação, e pela inserção no mercado de trabalho, buscam integrar as diferentes populaçôes que frequentam os espaços públicos da cidade; por um lado, as pessoas sem problemáticas específicas e, por outro, pessoas com a experiência do sofrimento psíquico, pessoas com deficiência, entre outros, considerados como população-alvo.

Foram participantes deste estudo terapeutas ocupacionais que se disponibilizaram e estavam atuando nos Ceccos, por ser a convivência um importante dispositivo para a Terapia Ocupacional (TO) na potencialização da vida ocupacional ${ }^{8}$.

Dos 24 Ceccos existentes, em 13 contabilizamos a presença de 24 terapeutas ocupacionais, entre os quais foram entrevistados 22 no período de março a julho de 2019. As entrevistas tiveram duração variada de 18 a 150 minutos. 
Utilizamos a entrevista semiestruturada com roteiro prévio que abordou os principais aspectos: percepção dos estigmas; experiências com potencialidade de enfrentamento dos estigmas; barreiras e propostas para a diminuição dos estigmas; manejo específico e contribuição da TO. Os textos transcritos foram analisados pelo discurso que estuda a produção da linguagem como uma atividade ancorada em um contexto e busca evidenciar não o conteúdo, mas o sentido do discurso, os significados presentes no texto, bem como as relaçóes entre os sujeitos e os sentidos atribuídos por eles aos acontecimentos sociais, históricos e culturais?.

Procedemos à leitura exaustiva dos textos, à identificação dos dispositivos analíticos ${ }^{10}$. Posteriormente, organizamos o material em recortes e segmentamos em unidades de significação ${ }^{11}$ como resposta aos objetivos colocados, à percepção acerca da estigmatização e às ações, aos manejos e às propostas para o seu enfrentamento. Após essa primeira etapa da análise, realizamos a releitura e a revisão de cada uma das unidades de significação para buscar conexões entre os recortes e compreender os sentidos dos discursos.

A análise produziu resultados em unidades discursivas que representam fragmentos os quais correlacionam linguagem e situação; desse modo, cada recorte apresentado é um fragmento da situação discursiva, produzida em um dado contexto e no processo de interação pesquisadora e entrevistada, levando em consideração a natureza sócio-histórica ${ }^{11}$.

O projeto foi aprovado pelos Comitês de Ética e Pesquisa da Ufes (CEP/Ufes) e da Prefeitura Municipal de São Paulo (CEP/PMSP), por meio dos pareceres de números 3.073.643 e 3.085.796, respectivamente, respeitando-se assim os princípios éticos fundamentais adotados na abordagem aos colaboradores.

\section{Resultados e discussão}

O tempo de atuação dos terapeutas ocupacionais nos Ceccos variou entre oito meses e 27 anos. As experiências anteriores foram em serviços de saúde de forma geral - Unidade Básica de Saúde (UBS) - e também em serviços da assistência social (antiga Febem, Centro Comunitário, etc.), mas grande parte da atuação se deu em serviços especializados de Saúde Mental (Centros de Atenção Psicossocial, Ambulatórios de Saúde Mental, Hospital Psiquiátrico e outros). Além disso, seis profissionais participaram da criação dos Ceccos e um deles cursou sua trajetória profissional exclusivamente nesses serviços. Os trechos discursivos têm como identificação a letra E, sucedida pelo número da entrevista.

Os resultados que emergiram da análise do discurso referem-se a quatro unidades de significação, entre as quais apresentamos e discutimos, neste trabalho, as concepções sobre os estigmas e o processo de estigmatização, com base nos sentidos apresentados: barreiras para o enfrentamento dos estigmas, tipos, consequências e possibilidades.

Preconceito e discriminação apresentam um enfoque maior em raça e etnia ${ }^{12}$, já o estigma teve origem com os estudos de Goffman², que incluíram a sociedade no processo de formação dos estigmas, diferenciando-a do conceito antigo grego. No entanto, estigma e preconceito, apesar de suas origens epistemológicas diferentes, são muitas vezes utilizados como sinônimos, pois têm sido conceituados como processos profundamente semelhantes ${ }^{13}$, como podemos verificar nos discursos abaixo, ao denunciar a dificuldade de enfrentamento e desvelar a exclusão social: 
A questão da estigmatização, o preconceito, né, que existe em relação às pessoas, ele é uma coisa bastante intensa, bastante forte, ainda, infelizmente eu acho que na nossa sociedade ainda é bastante forte. (E15)

O preconceito existe e é ainda muito grande, né, é um sofrimento psíquico imenso, né, e eu acho, que a sociedade ainda não está preparada para lidar com isso, por mais que a gente fala, "não, tem a questão da inclusão", pra mim a inclusão é linda no papel, né, na prática ela funciona muito pouco... (E17)

A Reforma Psiquiátrica Brasileira é um processo complexo de mudança social e tem como objetivo final o cuidado em liberdade e o respeito às diferenças; com a "transformação social do lugar da loucura" ${ }^{14} \mathrm{e}$ a inclusão social, produziu inúmeras e importantes experiências que fizeram e fazem o enfrentamento dos estigmas. Assim, a Reforma Psiquiátrica é a base, a sustentação para qualquer direcionamento que compete à diminuição e ao trabalho antiestigma em torno das pessoas com sofrimento psíquico e, nesse sentido, é reconhecida nos discursos dos participantes que afirmam a persistência dos estigmas:

Ainda é um trabalho de formiguinha, a gente passou por toda a Reforma Psiquiátrica, mas ainda assim o preconceito... (E17)

Como toda transformação e mudança de paradigma, é preciso de tempo. Temporalidade atualmente ameaçada por graves retrocessos no que se refere ao direcionamento da Política Nacional de Saúde Mental, Álcool e outras Drogas. O documento produzido e divulgado pelo Ministério da Saúde ${ }^{15}$ afirma recentes portarias e resoluções que representam a retomada da institucionalização como uma perspectiva de cuidado, pois comunidades terapêuticas de viés religioso ganham destaque para a problemática do uso abusivo de álcool e outras drogas, assim como o incentivo declarado ao uso de eletroconvulsoterapia com verba do Sistema Único de Saúde (SUS) e o reajuste dos valores nas internações psiquiátricas. Esse cenário tem como base o atual contexto macropolítico expresso nos discursos com preocupação, pois afeta a temática da estigmatização e seu enfrentamento:

Tá difícil de enxergar uma, uma possibilidade de mudança a curto prazo, sabe, eu acho que nós estamos vivendo um processo muito ruim aí na nossa sociedade, que é de retroceder muitas, muitas políticas públicas, né, voltadas pra essas questóes, e os apoios, as pessoas que tem dificuldades, enfim, isso está retrocedendo muita coisa, isso aí com certeza está relacionado ao governo atual... (E15)

Então precisa de política pública, sabe, pra você não deixar terminar o serviço, nós estamos caminhando pra fechar as portas, né, e aî́? Como é que fica, né? (E15) 
Com a discussão da Reforma da Previdência no Congresso Nacional foi possível observar o aumento do número de pedidos de aposentadorias no país, divulgado em mais de $115 \%$ em relação a $2018^{16}$. Cenário que comparece nos discursos como preocupação em relação à diminuição das equipes; não havia perspectiva de reposição dos recursos humanos para os Ceccos que, até aquele momento, faziam parte da administração direta da Prefeitura Municipal de São Paulo.

No cenário federal, as medidas tomadas com base em uma agenda neoliberal autoritária, privativista, sobretudo a partir de 2016, amparadas solidamente pelas forças armadas, pelas corporaçốes de mídia, por parte da opinião pública e de organizaçốes religiosas que respondem a uma inflexão conservadora que é mundial, nesse momento vem resultando em consequências desastrosas, como o aumento do desemprego, a desconstrução do SUS e de outras políticas públicas, que impactam diretamente o campo da Saúde Mental ${ }^{17}$.

Não obstante as dificuldades do cenário macroestrutural, o enfrentamento dos estigmas e preconceitos também se fez presente nos discursos como um trabalho de persistência no nível microssocial, no cotidiano:

É um contrabalançar que tem que ir, tem que ir mudando, tem que ir enfrentando barreira e com isso você vai mudando o pensamento, mudando o pensamento, você muda o seu lugar onde você trabalha, você muda e você vai mudando, é uma coisa infinita e acho que com o estigma é mais ou menos esse trabalho que a gente tem que fazer... (E18)

Os discursos revelam, como possibilidade, a persistência no trabalho para a diminuição dos estigmas como cotidiano, coletivo e possível.

A clareza acerca dos tipos de estigma é um fator que pode auxiliar no seu enfrentamento. Os estigmas associados aos transtornos mentais e outras condiçôes se apresentam de maneiras diversas, como: social ou público, internalizado ou autoestigma, familiar, profissional e estrutural ${ }^{3}$.

Um dos efeitos mais negativos do estigma social é o estigma internalizado, que ocorre quando o indivíduo tem consciência do estigma a ele atribuído, concordando e aplicando a si próprio os estereótipos negativos sobre sua doença, levando a várias consequências, como a diminuição da autoestima e da autoeficácia, além dos sentimentos de culpa, angústia, raiva e autorreprovação, o que leva ao sentimento de ser menos digno de oportunidades e dificulta os esforços de independência e autonomia ${ }^{18}$. Os discursos refletem essa compreensão, sinalizam a percepção do peso de um diagnóstico e o uso que se faz dele como identificação devido à internalização dos estigmas:

Nossa é muito pesado ter o diagnóstico, qualquer um desses com quem a gente trabalha na verdade, tanto do psicótico, do esquizofrênico, do transtornado, do, seja o nome que for, do deficiente, né, tanto deficiente físico, deficiente mental, eles chegam com uma menos valia de si mesmo assustador, e a gente trabalha muito, nosso trabalho é muito voltado pra isso, pra essa, mudar essa cultura, tanto da imagem que ele tem de si, quanto o que os outros têm dele. (E12) 
A gente tem usuário que chega e se apresenta, né, 'eu sou fulano de tal, esquizofrênico', é comum de acontecer isso, e aí o trabalho da gente é de ir tentando quebrar um pouquinho isso e dizer pra ele que ele é o fulano de tal, independente de ter ou não recebido um diagnóstico, mas isso está tão incorporado nele que parece, é como se fosse o sobrenome, ele não consegue se identificar sem trazer isso, né, isso é lógico que vem com uma bagagem de sentimento, vem com um repertório de situaçôes de vida que tem um peso grande, né? (E10)

Os discursos revelam que a busca pelo isolamento resulta do autoestigma:

Conversando com as pessoas durante os atendimentos, o que a gente vê em geral é muito retraimento deles, né, eles têm medo de se expor, eles têm medo de se, de participar de coisas, e as pessoas... é, sei lá, não gostarem, né, discriminarem, discriminarem eles... (E11)

O isolamento é uma estratégia para evitar ainda mais sofrimento diante da rejeição sofrida, pois, além da vergonha, a pessoa que é estigmatizada percebe qualquer fonte potencial de mal-estar na interação social ${ }^{2}$. Esse comportamento é denominado de discriminação antecipatória e, além da baixa autoestima, há o sentimento de medo de vir a sofrer a discriminação experimentada, a rejeição e a desvalorizaçãa ${ }^{19}$.

E, para tanto, revela-se a persistência no trabalho do Cecco como um espaço de fortalecimento, com possibilidades de mudança:

A pessoa, ela ouve tanto que ela é incapaz, que ela não pode, que ela não consegue, que ela introjeta isso como uma verdade, e transformar isso é um trabalho longo, mas possível e muito bonito de se assistir a pessoa perceber suas possibilidades, né? (E12)

O estigma familiar também foi um aspecto bastante presente nos discursos, explicitando que a falta de apoio e a atribuição de estereótipos clássicos, incapacidade e inutilidade podem partir do núcleo social primário, para as pessoas com sofrimento psíquico intenso, mas não apenas, como também para as pessoas com algum tipo de deficiência física ou intelectual:

Tem aqui casos da família que a pessoa, que o usuário tem que passar o dia no parque porque é o máximo que ele vai fazer da vida dele, e quando a gente fala, "não, mas olha, dá pra fazer isso, ela pode ir lá, fazer uma atividade no Centro Cultural, ela pode vir aqui e ficar sentada no parque o dia inteiro, não tem sentido, vem aqui pra fazer xis coisa, vai ali na Casa de Cultura fazer outra coisa”, "ah não, vocês não sabem, vocês não entendem nada, porque ela tem problema, ela só vai conseguir fazer isso”. (E10) 
Em estudo realizado por meio da voz das pessoas com a experiência do sofrimento psíquico constatou-se que o estigma internalizado é agravado pela reação negativa da família, a qual como rede de suporte primordial precisa ser foco de intervenção constante para que se possam modificar as relaçóes ${ }^{20}$.

Outro tipo de estigma é apontado nos discursos, o estigma do profissional e a aceitação como uma possibilidade para não estigmatizar:

Os pacientes sempre relatam muito isso, né, que quando vão em qualquer médico, por exemplo, vai lá, vai no ginecologista, quando fala, né, do diagnóstico, do tratamento, já têm um outro olhar, os pacientes relatam muito isso, né, de ter essa coisa de ser, de não ser bem cuidados nos outros espaços, né, dos acessos negados, né, isso é um relato muito comum, né. (E19)

Eu acho que pra o profissional primeiro a gente tem que ser muito transparente, se ele tiver, né, assim, se ele não tiver esse olhar assim de, sem preconceito mesmo, sem estigmatizar o outro, sabe, de aceitar o outro como ele é né. (E8)

O estigma profissional foi estudado pela primeira vez em 1962 e a partir dele foi desenvolvida a escala para medição de estigma mais utilizada - Escala de Medidas de Atitudes e Opiniốes sobre Doença Mental (ODM). O estigma profissional como uma repercussão do estigma social, nos estudos mais atuais, pode significar uma atitude de crença de que a pessoa com transtorno mental é diferente de uma "pessoa normal", ocasionando diferença na atenção. Além disso, o pessimismo quanto ao prognóstico e os movimentos de distanciamento social, como atitudes negativas dos profissionais de saúde ${ }^{3}$, podem se fazer presentes.

É interessante notar nos discursos que a experiência de trabalho no Cecco também pode facilitar mudanças de postura do profissional:

O fato de trabalhar no Cecco é interessante, porque acho que vai desfazendo tanto, assim, essa, isso dentro da gente... (E6)

Se foi possível assimilar no cotidiano um sistema de preconceitos provocados pelas integraçốes sociais como um meio de manter a estabilidade e a coesão social, a libertação dos preconceitos processa-se em um nível individual, quando há a predisposição em negar a confiança nas próprias ideias, na medida em que o conhecimento e a experiência as contradigam de modo regular ${ }^{21}$. Assim, estar disposto ao encontro com o outro e a tornar a relação horizontalizada resulta em vínculos fortalecidos, como aponta o trecho discursivo abaixo: 
Lógico que nós temos as nossas dificuldades, não é uma coisa tão romântica assim, tão simples, né, mas se você, parte de você ter esse olhar, né, de não estigmatizar, de ver aquela pessoa como um cidadão, né, com seus direitos e deveres, se você, que você está aqui pra facilitar a convivência ou o desenvolvimento da cidadania dele, sabe, acho que é a partir daí ser transparente com ele, acho que é muito assim da transparência, de ser autêntico, sabe, acho que você ser autêntico... (E8)

O estigma social foi revelado de alguns modos nos discursos, sendo, no contexto do Cecco, menos frequentes as situações de estigmatização, sobressaindo a capacidade de acolhimento:

Tem, já muita gente já tem, já consegue entender qual que é a dinâmica do Cecco, qual a história do Cecco, qual população que a gente atende, então muitos e muitos casos, acolhem bastante esse público. Alguns acho que ainda têm algumas dificuldades, mas a maioria acolhe muito bem o público de saúde mental. (E4)

Mas também foram percebidos comportamentos discriminatórios entre os frequentadores:

Às vezes ainda a gente vê, porque a gente tem, atualmente tem uma demanda dos casos ditos bem loucos mesmo né, então as vezes você vê um ou outro olhando... (E2)

Sobretudo quando ocorrem momentos de crise:

Nós temos as duas situaçóes de acolhida muito grande de compreensão das diferenças e das particularidades, mas também, por exemplo, em algumas situaçôes aonde o frequentador, o nosso usuário, está com alguma dificuldade na adesão ao tratamento ambulatorial, entra numa fase de descompensação do quadro psiquiátrico, do quadro da saúde mental, da saúde não, da doença mental né, e começa apresentar alguma alteração de comportamento aqui, alguns se recolhem, se retraem, e as vezes falam, "não é melhor ele ir pro Caps?" (risos), essas são as falas que mais aparecem, os que também têm alguma questão de doença mental, falam, “aí eu acho que ele está sem tomar medicação!", então isso, isso fica muito claro nas questôes das alterações comportamentais que algumas vezes se manifestam aqui. (E1)

O discurso revela que ainda há um limite para a aceitação do outro na convivência. Em situaçốes como essa, o Caps em substituição ao Hospital Psiquiátrico e o tratamento medicamentoso são lembrados pelos frequentadores do Cecco. A crise e a medicação psicotrópica são signos da estigmatização, pois transmitem informaçôes que podem ter diferentes significados ${ }^{2}$ e são símbolos que marcam a identidade das pessoas com a experiência do sofrimento psíquico.

Nas situaçóes de atividade externa ao Cecco, são percebidos estranhamentos, mas também possibilidades de aceitação, por exemplo, por parte dos passageiros nos transportes utilizados: 
No ônibus eu vejo muito isso, que tem gente que fica olhando assim, daqui a pouco se encanta, começa a puxar assunto, quer conversar, e a fisionomia também é outra... (E14)

Emerge nos discursos também o estereótipo de periculosidade e a rejeição em torno das pessoas que fazem o uso de álcool e outras drogas e estão em situação de vulnerabilidade social, a população de rua, em comparação com outras populaçóes:

Principalmente com população em situação de rua, principalmente. Os deficientes mentais, essa coisa sempre, automaticamente eu sinto que já é algo mais do ajudar né, não tem uma repulsa, no sentido né, 'não me é estranho', nossa, a questão do 'ai, precisa de ajuda', né, desperta um sentimento mais assim, agora o transtorno mental desperta medo, e acho que mais ainda a população em situação de rua, o cara que tá fedido, o cara que tá ali na rua tem uma coisa que é perigoso, como o transtorno mental também né, é o louco que pode me pegar, me matar, me roubar... (E3)

Pessoas em situação de rua, eles trazem isso mais forte, principalmente, quem frequenta aqui que é morador em situação de rua e está em situação de uso de drogas. (E5)

Observa-se assim uma sobreposição de estereótipos, da loucura, do uso de substâncias psicoativas e do modo de vida nas ruas, resultando em processos de rejeição ainda mais intensos no contexto do próprio serviço.

O conteúdo de estereótipos e de atitudes estigmatizantes depende do grupo populacional que apresenta a estigmatização. As pessoas que fazem o uso de substâncias psicoativas são mais propensas a ser classificadas como um risco para outras pessoas, em comparação às pessoas com o diagnóstico de esquizofrenia ou de depressão ${ }^{22}$.

O estigma institucional ou estrutural é mais um tipo de estigma identificado nos discursos que se caracteriza pela negação ou por imposiçóes para o acesso aos direitos, como do uso gratuito do transporte coletivo ou, ainda, do afastamento do trabalho como benefícios garantidos por lei:

O médico dá uma declaração, você vai para o INSS, o INSS fala que você tem condiçôes de trabalhar, na firma ninguém quer você de volta né, principalmente se você teve algum episódio dentro da empresa, eles já dificilmente aceitam você de volta, e aí fica nessa briga né, não consegue um emprego, não consegue INSS e as pessoas ficam passando por situaçôes muito difíceis financeiramente, né. (E17) 
No acesso mesmo a muita coisa né, muita coisa “ah, porque não pode”, né, negação de benefícios às vezes, a gente falava, "meu Deus, né”, dificuldade nos trâmites, por exemplo, SPTrans, né, eles iam com um papel, aí cismaram uma época que queriam receitas, pra que, você está mandando de um CAPS um paciente né, pra ter um direito à isenção tarifária, por que quem está lá precisa saber que remédio toma, né, eu acho que isso é um estigma, né? (E19)

Como consequências do estigma estrutural que inclui as políticas governamentais e de instituiçóes privadas, que intencionalmente restringem oportunidades das pessoas em maior situação de vulnerabilidade, observa-se menos oportunidades de trabalho, educação, assistência médica e jurídica³ .

A estigmatização, como denunciado nos discursos, compromete a adesão e o acesso ao serviço de saúde, à escola, mas, sobretudo, à inserção no trabalho:

Para as questôes de transtorno, o que pega é você não estar no mercado de trabalho né, porque quando você está no mercado de trabalho, você tá incluído né, de uma certa maneira você faz parte dessa sociedade né, seja lá que emprego, até emprego meia boca, mas você se sente incluído, eu acho que pra eles o estigma que a gente estava falando é isso, quando você começa e você é cortado dessa questão do trabalho, acho que é uma marca muito difícil de lidar né. (E9)

E, ainda, os jovens, em comparação com os adultos, são os mais prejudicados diante das impossibilidades de trabalho:

Eu sinto muito, assim, do jovem, da questão de trabalho, de hoje eles passam muito por isso, essa questão de não ter um benefício, ou cancelamentos de benefícios, essas coisas, mas que eles também não conseguem trabalho. (E8)

Para além dos fenômenos tradicionais, como desemprego, carreira e sofrimento no trabalho, as relaçôes entre juventude e trabalho são um dos temas emergentes, tais como as organizaçôes contemporâneas do trabalho-informalidade, Economia Solidária e diversidade no mundo do trabalho. A juventude é a faixa etária mais atingida pela precarização do trabalho e pelo desemprego ${ }^{23}$. Soma-se a isso a dificuldade de aceitação no mercado de trabalho por alguma situação, como o uso de substâncias psicoativas, $o$ cumprimento de medidas socioeducativas, ou a presença de algum diagnóstico como de transtorno mental ou Aids/HIV, aspectos que são passíveis de estigmatização, somando-se a eles a condição de desempregado.

O que resulta desse processo é a exclusão social, seja pela negação de direitos e a impossibilidade de participar do jogo das trocas sociais, afetivas e materiais, seja pelo cerceamento da liberdade com a internação, o que agrava ainda mais o sofrimento psíquico das pessoas, como pode ser reconhecido pelos discursos:

A família, às vezes, não consegue muito lidar, a gente vê até hoje muitos pedidos de internação... (E10) 
O maior prejuízo é da exclusão mesmo, da exclusão, do isolamento, da marca né, do diferente, desvalorizado daquele que não pode, que não é capaz, eu acho que é, e o grande sofrimento desse isolamento por conta disso né, do isolamento, do preconceito. (E16)

As consequências dos estigmas podem trazer maior desvantagem do que a própria condição primária de adoecimento para as pessoas ${ }^{24}$. Os efeitos do fenômeno discriminatório já foram alvo de estudos que revelaram que o estresse provocado ocasiona sofrimento psicológico, adoção de comportamentos negativos, alterações nos ritmos fisiológicos do organismo, consumo de substâncias psicoativas, e resulta ainda mais em condiçốes que afetam o processo de saúde-doença, como estresse crônico, ansiedade, elevação da pressão arterial, diabetes e doença renal ${ }^{25}$.

O processo de estigmatização é complexo, abrange todos os âmbitos relacionais e, nessa dinâmica, do estigma estrutural à interiorização da rejeição, os prejuízos no cotidiano das pessoas são claros. O impedimento ou dificuldade de estabelecimento de relaçóes sociais e afetivas denota o estreitamento da rede social das pessoas, e o trabalho da equipe, mais uma vez, é apresentado como uma possibilidade de enfrentamento:

Nós temos alguns usuários aqui né, frequentadores aqui do serviço, que pontuam o quanto isso marca, o quanto isso mexe no dia a dia deles, e daí o nosso trabalho é estimulá-los a de alguma forma lidar com a situação e enfrentar essa situação e reagir a tudo isso... (E5)

$\mathrm{Na}$ América Latina, ainda que a abordagem do fenômeno do estigma seja reconhecida como uma prioridade para as políticas de Saúde Mental, e as evidências demonstrem que, nos países latino-americanos, o desconhecimento e os estereótipos em torno das pessoas com sofrimento psíquico resultam em atos discriminatórios e de exclusão social, os projetos antiestigmas desenvolvidos para diminuir as manifestaçôes e consequências do estigma são escassos ${ }^{26}$. Como a realidade brasileira é marcada por profunda desigualdade social, as estratégias devem perpassar, necessariamente, pelos diferentes aspectos da aquisição de direitos sociais e de cidadania.

Não obstante o cenário favorável ao recrudescimento da estigmatização e da exclusão social como principal barreira, como apontado anteriormente, possibilidades para o enfrentamento da estigmatização são desveladas nos discursos. A convivência como importante ferramenta de um equipamento público de saúde apresenta potencialidade de enfrentamento e resistência ao estigma. Os encontros produzidos por oficinas e açóes, mediadas por um fazer facilitado por uma equipe que tem como expertise o manejo da convivência, a inventividade e a criatividade, em um processo de produção de saúde e de vida sem foco em adoecimentos ou sofrimentos de diferentes naturezas, reafirmam os caminhos possíveis, propostos e desejados no enfrentamento da estigmatização. 


\section{Considerações finais}

Os discursos denunciaram mais uma vez a exclusão social das pessoas que apresentam o sofrimento psíquico ou outra condição que é tomada como estigmatizante. Ainda revelaram que os profissionais identificam empiricamente os diferentes tipos de estigmas e seus estereótipos.

No que tange à percepção do processo de estigmatização e seus prejuízos, os discursos apresentaram uma coerência com a literatura produzida acerca dos estigmas. Nesse sentido, apesar da construção histórica e social em que se ancoram as ideologias presentes de modo geral, é no processo da Reforma Psiquiátrica e do campo da Saúde Coletiva que se baseiam a compreensão do complexo processo saúde-doença, o protagonismo do sujeito e a inclusão social.

O prejuízo nos relacionamentos sociais e afetivos, bem como a dificuldade em relação aos acessos a bens comuns, mas, sobretudo, a dificuldade de inserção no trabalho como uma importante consequência no cotidiano das pessoas, foi enfatizada e problematizada em vários discursos, em diferentes momentos, o que confirma a relevância do aspecto trabalho no enfrentamento da estigmatização e reflete historicamente o projeto dos Ceccos que tinha, como proposição inicial, a reinserção dos usuários no mundo do trabalho por meio da criação de cooperativas sociais, anteriormente ao movimento de Economia Solidária. Assim, não mais com a expectativa de cooperativa, mas ainda perseguindo o trabalho como uma ferramenta de inclusão social, muitos dos Ceccos visitados contemplavam atividades de geração de renda, Economia Solidária e experiências de capacitação para o trabalho.

Para além disso, os participantes mostraram-se atentos ao sofrimento ocasionado pela discriminação e julgam-se agentes que podem contribuir com suas ações no enfrentamento dos estigmas. Não obstante os problemas estruturais e macrossociais presentes, persistem e acreditam no trabalho do Cecco, um microcontexto com possibilidade de transformaçóes possíveis de si mesmos, das pessoas a que atendem e daqueles que entram verdadeiramente em contato com as pessoas em situação de algum tipo de vulnerabilidade social.

Apontamos como limite do estudo a participação de apenas uma das categorias profissionais que compóem as equipes dos Ceccos. Trata-se de um limite que tem relação com a proposição inicial. Sugerimos que futuras pesquisas possam partir dos discursos da população usuária desses e de outros serviços, com o uso de instrumentos tanto qualitativos como quantitativos para mensuração da estigmatização ou da inclusão social. 


\section{Contribuição das autoras}

Ambas as autoras participaram ativamente de todas as etapas de elaboração do manuscrito.

\section{Conflito de interesse}

As autoras não têm conflito de interesse a declarar.

\section{Direitos autorais}

Este artigo está licenciado sob a Licença Internacional Creative Commons 4.0, tipo BY (https://creativecommons.org/licenses/by/4.0/deed.pt_BR).

\section{(cc) BY}

\section{Editora}

Roseli Esquerdo Lopes

Editora associada

Fatima Corrêa Oliver

\section{Submetido em}

07/07/20

Aprovado em

$29 / 11 / 20$

\section{Referências}

1. Avdibegovic E, Hasanovic M. The stigma of mental illness and recovery. Psychiatr Danub. 2017; 29(5):900-5.

2. Goffman E. Estigma: notas sobre a manipulação da identidade deteriorada. Rio de Janeiro: Zahar; 1982.

3. Ferreira MS, Carvalho MCA. Estigma associado ao transtorno mental: uma breve reflexão sobre suas consequências. Rev Interdiscip Estud Saude. 2017; 6(2):192-201.

4. Corrigan P, Gelb B. Three programs that use mass approaches to challenge the stigma of mental illness. Psychiatr Serv. 2006; 57(3):393-8.

5. Brasil. Portaria GM/MS no 3.088, de 23 de Dezembro de 2011. Institui a Rede de Atenção Psicossocial para pessoas com sofrimento ou transtorno mental e com necessidades decorrentes do uso de crack, álcool e outras drogas, no âmbito do Sistema Único de Saúde (SUS). Diário Oficial União. 26 Dez 2011.

6. São Paulo. Portaria no 964, de 27 de Outubro de 2018-SMS.G. Regulamenta os Centros de Convivência e Cooperativa e estabelece diretrizes para o seu funcionamento. São Paulo: Secretaria Municipal da Saúde; 2018. 
7. Santos JC. O estigma da doença mental: compreensão e ações dos trabalhadores dos CAPS [dissertação]. São Paulo: Universidade de São Paulo; 2013.

8. Ferigato SH, Silva CR, Lourenço GF. A convivência e o com-viver como dispositivos para a Terapia Ocupacional. Cad Ter Ocup UFSCar. 2016; 24(4):849-57.

9. Lima DWC, Vieira AN, Gomes AMT, Silveira LC. Historicidade, conceitos e procedimentos da análise do discurso. Rev Enferm UERJ. 2017; 25:e12913.

10. Gomes AMT. Do discurso às formaçôes ideológica e imaginária: análise de discurso segundo Pêcheux e Orlandi. Rev Enferm UERJ. 2007; 15(4):555-62.

11. Orlandi EP. Segmentar ou recortar? In: Orlandi EP. Linguística - questóes e controvérsias. Uberaba: Publicação do curso de Letras do Centro de Ciências Humanas e Letras das Faculdades Integradas de Uberaba; 1984. p. 9-27.

12. Parker R. Intersecções entre estigma, preconceito e discriminação na saúde pública mundial. In: Monteiro S, Villela W. Estigma e saúde. Rio de Janeiro: Editora Fiocruz; 2013. p. 25-46.

13. Phelan J, Link B, Dovidio J. Estigma e preconceito: um animal ou dois? In: Monteiro S, Villela W. Estigma e saúde. Rio de Janeiro: Fiocruz; 2013. p. 183-201.

14. Amarante P. Saúde mental e atenção Psicossocial. 4a ed. Rio de Janeiro: Fiocruz; 2015.

15. Brasil. Ministério da Saúde. Nota técnica no 11/2019-CGMAD/DAPES/SAS/MS. Esclarecimentos Sobre as Mudanças na Política Nacional de Saúde Mental e nas Diretrizes da Política Nacional sobre drogas. Brasília: Ministério da Saúde; 2019.

16. Quintino L. Com reforma da Previdência, pedidos de aposentadoria disparam 115\%. Veja [Internet]. 2019 [citado 22 Maio 2020]. Disponível em: https://veja.abril.com.br/ economia/com-reforma-da-previdencia-pedidos-de-aposentadoria-disparam-115/

17. Delgado PG. Reforma psiquiátrica: estratégias para resistir ao desmonte. Trab Educ Saude. 2019; 17(2):1-4.

18. Soares RG, Nery FC, Silveira OS, Noto AR, Ronzani TM. A mensuração do estigma internalizado: revisão sistemática da literatura. Psicol Estud. 2011; 16(4):635-45.

19. Pimentel FA. Esquizofrenia e participação social: a percepção do portador em relação ao estigma e discriminação [dissertação]. São Paulo: Universidade de São Paulo; 2009.

20. Nascimento LA, Leão A. Estigma social e estigma internalizado: a voz das pessoas com transtorno mental e os enfrentamentos necessários. Hist Cienc Saude Manguinhos. 2019; 26(1):103-21.

21. Heller A. O cotidiano e a história. São Paulo: Paz e Terra; 2004.

22. Stuart H. Reducing the stigma of mental ilness. Glob Ment Health. 2016; 3(17):1-14.

23. Ribeiro M. Problemas contemporâneos para a psicologia do trabalho e das organizaçóes. In: Orejuela JJG. Psicologia de las organizaciones y del trabajo: apuestas de investigacion. Cali: Editorial Bonaventuriana; 2014. p. 47-78.

24. Thornicroft G, Rose D, Kassam A, Sartorius N. Stigma: ignorance, prejudice or discrimination? Br J Psychiatry. 2007; 190:192-3.

25. Badalotti TS, Toassi RFC, Celeste RK. O enfrentamento ao fenômeno discriminatório em uma população de adultos. Physis. 2019; 29(4):1-23.

26. Tapia FM, Schilling S, Escobar ET, Abeldaño RA, Gallo VV. Programas para reducir estigma hacia la enfermedad mental: lecciones para latinoamérica. In: Fernández AR, Enders J. Experiencias y reflexiones en salud mental comunitaria. Córdoba: Kronos; 2014. p. 257-86. 
The negative effects of stigma are a serious problem worldwide and efforts have therefore been made to enhance awareness and understanding of strategies to tackle this issue. Within the scope of public health policy, Centers for Coexistence and Cooperatives promote and enhance interaction between people from both vulnerable and non-vulnerable groups. This study sought to understand concepts of the process of stigmatization through the lens of professionals working in these centers. The discourse analysis resulted in units of meaning that included understandings about the types and consequences of stigmas and how to tackle this issue. Despite structural and macro social problems, there is persistence in the daily work in view of the possibility of transformation observed in the context of the service.

Keywords: Social stigma. Public health. Mental health. Health services.

Los efectos negativos del estigma constituyen un problema significativo en todo el mundo y, para ello, se busca aumentar la concienciación y comprensión sobre las estrategias más eficaces para combatir los estigmas. En el ámbito de las políticas públicas de salud, la convivencia que promueve e intensifica el contacto entre las personas, con o sin vulnerabilidad específicas, es promovida intencionalmente por los Centros de Convivencia y Cooperativas. El objetivo de este artículo es comprender las concepciones sobre el proceso de estigmatización a partir de la visión de profesionales. El análisis del discurso resultó en unidades de significación, entre ellas las comprensiones alrededor de tipos, consecuencias y posibilidades para enfrentar los estigmas. A pesar de los problemas estructurales y macrosociales presentes, existe la persistencia en el trabajo cotidiano ante las posibilidades de transformación observadas en el contexto del servicio.

Palabras clave: Estigma social. Salud pública. Salud mental. Servicios de salud. 


\section{(e) interface \\ comunicação, saúde, educação}

https://www.interface.org.br

eISSN 1807-5762

\section{Errata}

No artigo Estigmatização: consequências e possibilidades de enfrentamento em Centros de Convivência e Cooperativas, com número DOI: 10.1590/interface.200474, publicado no periódico Interface - Comunicação, Saúde, Educação, 2021; 25: e200474:

Onde se lia:

Isabela Oliveira Lussi

Leia-se:

Isabela Aparecida de Oliveira Lussi

Creative Commons License This is an Open Access article distributed under the terms of the Creative Commons Attribution License, which permits unrestricted use, distribution, and reproduction in any medium, provided the original work is properly cited.

\section{(cc) BY}

Leão A, Lussi IAO. Estigmatização: consequências e possibilidades de enfrentamento em Centros de Convivência e Cooperativas. Interface (Botucatu). 2021; 25: e210230 